\title{
Comunicação
}

[Comunication]

\section{Ocorrência do leite instável não ácido no noroeste do Rio Grande do Sul}

[Occurrence of unstable non-acid milk in the Northwest of Rio Grande do Sul]

\author{
M.B. Zanela ${ }^{1}$, M.E.R. Ribeiro ${ }^{2}$, V. Fischer ${ }^{3}$, J.F. Gomes ${ }^{2}$, W. Stumpf Jr. ${ }^{2}$ \\ ${ }^{1}$ Faculdade de Veterinária/LEITECIA - UFRGS \\ Av. Bento Gonçalves, 9090 \\ 91540-000 - Porto Alegre, RS \\ ${ }^{2}$ Embrapa Clima Temperado - Pelotas, RS \\ ${ }^{3}$ Departamento de Zootecnia - UFRGS - Bolsista do CNPq
}

O teste do álcool é utilizado para medir a estabilidade física do leite, determinando seu aceite ou sua rejeição por parte da indústria, no momento da coleta (Barros, 2001). O leite instável não ácido (LINA) caracteriza-se pela perda de estabilidade da caseína, resultando em sua precipitação na prova do álcool, sem, entretanto, haver acidez titulável elevada (acima de $\left.18^{\circ} \mathrm{D}\right)$. As causas do LINA ainda não estão totalmente esclarecidas. A precipitação do leite ao teste do álcool resulta, muitas vezes, na rejeição do leite pela indústria, com prejuízos ao produtor.

Alterações dessa natureza foram relatadas em diferentes países como no Irã (Sobhani et al., 1998), em Cuba (Ponce Ceballo, 2000), no Uruguai (Barros et al., 1999) e na Argentina (Negri et al., 2001). No Brasil, foram verificadas por Marques (2004) e Zanela (2004).

Os objetivos deste trabalho foram verificar a ocorrência do LINA no noroeste do Rio Grande do Sul, avaliar sua variação nos meses em estudo e seus efeitos sobre a composição do leite.

O trabalho foi realizado entre os meses de setembro de 2002 a agosto de 2003. Nesse período, foram monitoradas, mensalmente, cerca de 200 unidades de produção leiteira (UPL), que entregam leite para a cooperativa local, compreendendo cerca de $33 \%$ dos produtores da região.
Mensalmente, colheu-se uma amostra de leite do tanque resfriador de cada UPL, pelos transportadores, após a homogeneização, e não foram incluídas amostras de leite rejeitadas pelo transportador no momento da coleta. Foram realizados os testes de: acidez titulável em graus Dornic $\left({ }^{\circ} \mathrm{D}\right)$, precipitação à prova do álcool $76 \%$ e redutase. As amostras foram classificadas em: alcalina (acidez $<14^{\circ} \mathrm{D}$ e estável ao álcool); normal (acidez $14-18^{\circ} \mathrm{D}$ e estável ao álcool); ácida (acidez $>18^{\circ} \mathrm{D}$ e instável ao álcool) e LINA (acidez $\leq 18^{\circ} \mathrm{D}$ e instável ao álcool).

Uma alíquota das amostras de leite foi encaminhada ao laboratório para a determinação da composição química (gordura, proteína bruta, lactose e extrato seco total), por meio de espectrofotometria por radiação infravermelha e contagem de células somáticas (CCS), por citometria de fluxo.

As UPL foram classificadas de acordo com a produção de leite diária entregue na cooperativa em: grupo 1 (G1, $\leq 30$ litros/dia), grupo 2 (G2: 30 - 79 litros), grupo 3 (G3, 80 - 14 litros), grupo 4 (G4, 150 - 49 litros) e grupo 5 (G5, $\geq 50$ litros).

O delineamento experimental adotado foi $\mathrm{o}$ completamente ao acaso, em arranjo fatorial desbalanceado. A variação da composição química do leite foi avaliada entre o LINA e o leite normal, com exclusão das amostras alcalinas e ácidas. Para isto, foi utilizada a

Recebido em 20 de setembro de 2008

Aceito em 18 de maio de 2009

E-mail: maira.zanela@ufrgs.br 
análise da variância, por meio do procedimento GLM do SAS/1989, utilizando-se como fonte de variação LINA ( $\mathrm{n}=2$; com e sem LINA) e meses $(n=12)$. A interação LINA x mês de coleta foi retirada do modelo estatístico por não apresentar resultado significativo em nenhuma das análises realizadas, e foi utilizado o nível de significância de 0,05. Calculou-se a ocorrência de LINA nos grupos de produção de leite no período estudado e estimou-se a correlação entre LINA e CCS e entre LINA e redutase.

Foram analisadas 2.396 amostras de leite. A ocorrência de LINA foi de 55,2\%, estatisticamente diferente $(\mathrm{P}=0,0001)$ das amostras negativas ao LINA (44,8\%), que compreenderam $36,9 \%$ de amostras normais, $6,1 \%$ alcalinas e $1,8 \%$ ácidas. Estes resultados aproximam-se dos encontrados por Marques (2004), que avaliou a ocorrência do leite instável na bacia leiteira de Pelotas, RS. No referido trabalho, foram analisadas 9.892 amostras de leite, no período de abril de 2002 a setembro de 2003, e ocorrência de LINA foi de 58\%.
Com relação à acidez, o LINA não abrangeu o leite com acidez titulável elevada. A caracterização do LINA de acordo com a variação de acidez titulável foi: $44,3 \%$ das amostras apresentaram acidez normal, de 14 a $18^{\circ} \mathrm{D}, 7,7 \%$ entre 13 e $14^{\circ} \mathrm{D}$ e $3,2 \%<13^{\circ} \mathrm{D}$. Ponce Ceballo e Hernandez (2001) denominaram o leite instável como síndrome do leite anormal (SILA). Segundo esses autores, para estabelecer um caso de SILA, a prova do álcool deve ser positiva e a acidez titulável menor que $13^{\circ} \mathrm{D}$, ou o pH deve ser elevado. Conforme os resultados, apenas 3,2\% dos casos corresponderam aos padrões estabelecidos por Ponce Ceballo e Hernandez (2001) para o SILA. A maior parte do LINA aconteceu dentro dos limites estabelecidos como normais para acidez do leite.

A porcentagem de LINA variou durante os meses em estudo (Fig.1), sendo mais elevada no final do verão e início do outono (fevereiro e março). Diversos autores identificaram a ocorrência de variações sazonais na frequência do leite instável. Entretanto, os períodos de maior ocorrência podem variar de acordo com a região em estudo.

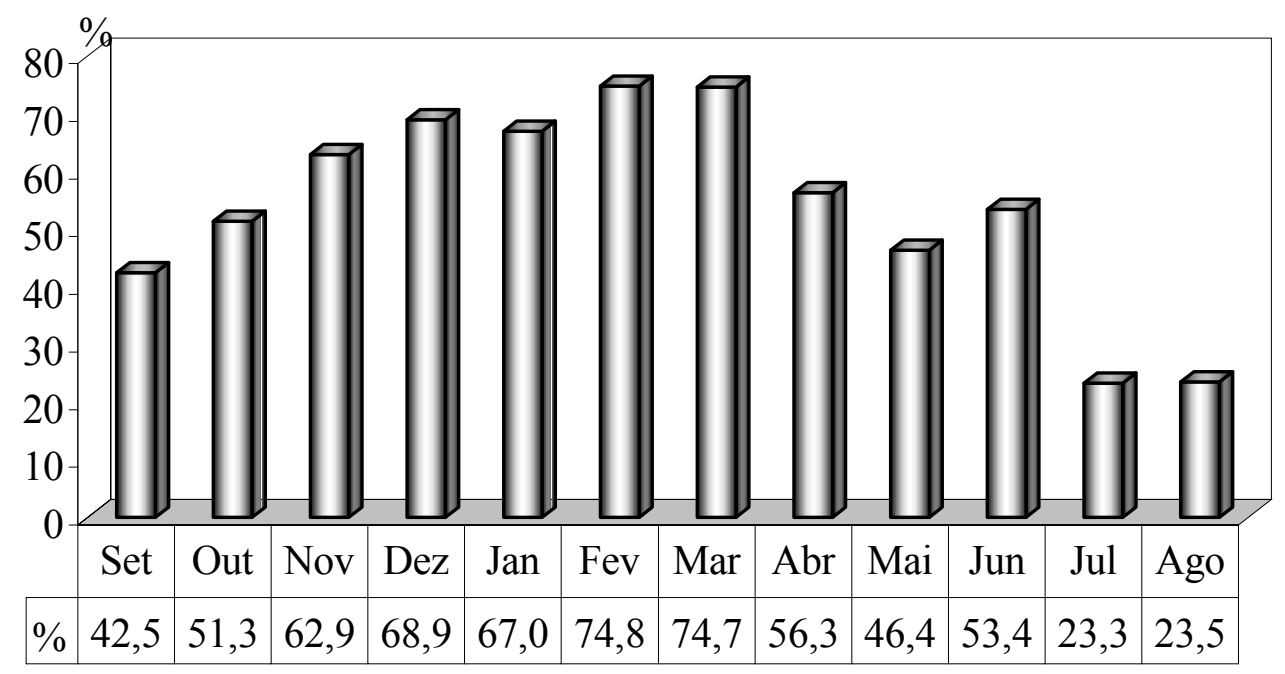

Figura 1. Ocorrência de leite instável não ácido segundo o mês de coleta de amostra no noroeste do Rio Grande do Sul.

No Uruguai, Barros (2001) verificou que as alterações na estabilidade do leite foram mais frequentes nos meses de outono, nas mudanças de estação de inverno para primavera e nos períodos de seca. Em Cuba (Ponce Ceballo e Hernandez, 2001), as alterações foram verificadas nos meses de março e abril, que coincidem com a maior escassez de alimento e baixa condição corporal dos animais. $\mathrm{Na}$ bacia leiteira de Pelotas, o LINA foi maior no mês de abril e menor em setembro, concentrando a maior ocorrência nos meses de outono (Marques, 
2004), o que coincidiu com períodos de menor disponibilidade de alimentos.

Para avaliação da composição química das amostras de leite com e sem LINA, foram excluídas as alcalinas e as ácidas, o que resultou em 2.205 amostras analisadas. A porcentagem de gordura não variou entre leite normal e LINA, entretanto os teores de proteína bruta, lactose, sólidos totais e sólidos desengordurados foram mais baixos no LINA (Tab. 1).

Tabela 1. Porcentagem dos componentes do leite normal e leite instável não ácido (LINA)

\begin{tabular}{lccc}
\hline Componentes $(\%)$ & Normal & LINA & $\mathrm{P}=\mathrm{F}$ \\
\hline Gordura & 3,39 & 3,43 & 0,0723 \\
Proteína bruta & 3,05 & 3,01 & 0,0001 \\
Lactose & 4,39 & 4,29 & 0,0001 \\
Sólidos totais & 11,78 & 11,65 & 0,0001 \\
Sólidos desengordurados & 8,39 & 8,23 & 0,0001 \\
\hline
\end{tabular}

$(\mathrm{P}<0,05)$.

A porcentagem de proteína bruta foi menor no LINA em relação ao leite normal, e estes resultados assemelham-se aos encontrados por Ponce Ceballo e Hernandez (2001) e Marques (2004). Barros (2001) verificou aumento nos teores de proteína bruta no leite instável; outros não identificaram diferenças significativas entre o leite normal e o instável (Sobhani et al., 1998; Negri et al., 2001). Acredita-se que a diminuição da proteína esteja associada à redução da caseína do leite, devido à menor disponibilidade de nutrientes da dieta. Não se dispõe de dados conclusivos a respeito da dieta dos animais que permitam confirmar essa hipótese. Além disso, neste trabalho, não foi possível determinar o teor de caseína, porém outros autores encontraram redução nesse componente (Ponce Ceballo e Hernandez, 2001).

O teor de lactose no LINA foi mais baixo que no leite normal. No caso da lactose, parece haver um consenso entre os autores de que o leite instável apresenta teores mais baixos de lactose (Sobhani et al.,1998; Barros, 2001; Ponce Ceballo e Hernandez, 2001; Marques, 2004), sugerindo uma associação com subnutrição.

A porcentagem de sólidos totais e sólidos desengordurados foi mais baixa no LINA, possivelmente devido à diminuição de proteína $\mathrm{e}$ lactose, o que também ocorreu com os resultados de Ponce Ceballo e Hernandez (2001). Entretanto, diferem principalmente dos encontrados por Barros (2001), que encontrou aumento na concentração desses componentes. Convém salientar que esse autor trabalhou com amostras de leite de animais individuais, o que pode ter causado a variação nos resultados.

Quanto à gordura, não houve diferença entre LINA e leite normal. Marques (2004) e Barros (2001) verificaram aumento no teor de gordura do leite instável. Outros autores (Sobhani et al., 1998; Negri et al., 2001; Ponce Ceballo e Hernandez, 2001) não verificaram variação significativa para gordura. Dos componentes do leite, o teor de gordura é o que mais pode variar em função da alimentação, isto é, em geral diminui com o aumento do volume de produção (Mühlbach et al., 2000).

Os meses de fevereiro e março de 2003 corresponderam a baixas produções, média de 76 e $68 \mathrm{~L} / \mathrm{UPL} /$ dia, respectivamente, e foram os de maior ocorrência de LINA, 74,8 e 74,7\%, respectivamente; os meses de menor ocorrência de LINA foram julho e agosto de 2003, 23,3 e $23,5 \%$, respectivamente, e corresponderam a elevadas produções de leite, 103,5 e $110,8 \mathrm{~L} / \mathrm{UPL} /$ dia.

De acordo com a produção média diária entregue para a cooperativa da região, as unidades de produção de leite monitoradas foram divididas em grupos. Assim, a porcentagem média de LINA foi: G1 $(60,8 \%) ; \quad$ G2 $(62,6 \%) ; \quad$ G3 $(53,7 \%)$; G4 $(30,5 \%)$ e G5 $(5,9 \%)$. Estes resultados assemelham-se aos de Marques (2004), que verificou redução do LINA conforme aumentou o da produção. 
Houve correlação positiva entre LINA e CCS $(\mathrm{r}=0,05, \quad \mathrm{P}=0,015$ e $\mathrm{n}=2.220)$ e correlação negativa entre LINA e redutase $(\mathrm{r}=-0,111$, $\mathrm{P}=0,0001$ e $\mathrm{n}=2.033$ ), entretanto os coeficientes de correlação foram muito baixos, não permitindo maiores inferências.

Donatele et al. (2003) sugeriram não haver relação entre positividade do leite ao teste do alizarol $72 \%$ e número de células somáticas. No referido trabalho, em $61,7 \%$ das amostras positivas ao alizarol, o número de células somáticas foi menor que $3,0 \times 10^{5} \mathrm{cel} / \mathrm{mL}$ de leite. Esses autores também não encontraram envolvimento de bactérias na causa da instabilidade do leite in natura no teste do alizarol 72\%. Negri et al. (2001) encontraram menor CCS no leite instável do que no leite normal. Não foram detectadas diferenças significativas na contagem bacteriana total. Por outro lado, Marques (2004) identificou maior CCS no LINA, $4,6 \times 10^{5} \mathrm{cel} / \mathrm{mL}$, do que no leite normal, $4,0 \times 10^{5} \mathrm{cel} / \mathrm{mL}$.

Assim, a ocorrência do LINA na região de Panambi foi elevada, 55\%, ocorreu variação sazonal, sendo o final de verão o período mais crítico. Sua composição apresenta-se mais diluída do que a do leite normal, com menores teores de proteína bruta, lactose, sólidos desengordurados e sólidos totais.

Palavras-chave: composição leite qualidade leite, estabilidade, teste do álcool

\section{ABSTRACT}

The unstable non-acid milk (UNAM) is characterized by loss of casein stability, which results in its precipitation at the alcohol test even though titratable acidity be lower than $18^{\circ} \mathrm{D}$. This trial aimed to estimate the occurrence of UNAM in the Northwest of Rio Grande do Sul, state and to verify seasonal variation and its effects on milk composition. From September 2002 to August 2003, approximately 200 dairy farms were monthly monitored. Milk samples from bulk tank were collected and analyzed for titratable acidity; precipitation at alcohol $76 \%$ test; percentages of fat, crude protein, lactose, total solids; and somatic cells count, totalizing 2,396 milk samples. UNAM occurrence was 55.2\%, being highest in February and March 2002. UNAM occurrence was reduced as milk production of farms increased. Fat percentage did not vary between normal milk and UNAM. However, crude protein, lactose, total solids, and solids non-fat contents were lower in UNAM than in normal milk.

Keywords: milk composition, milk quality, stability, alcohol test

\section{REFERÊNCIAS BIBLIOGRÁFICAS}

BARROS, L. Transtornos metabólicos que afetam a qualidade do leite. In: GONZÁLEZ, F.H.D.; DÜRR, J.W.; FONTANELI, R.S. (Ed.). Uso do leite para monitorar a nutrição $e$ metabolismo de vacas leiteiras. Porto Alegre: UFRGS, 2001. p.44-57.

BARROS, L.; DENIS, N.; GONZALEZ, A. et al. Prueba del alcohol em leche y relación con calcio iónico. Pract. Vet., v.9, p.315, 1999.

DONATELE, D.M.; VIEIRA, L.F.P.; FOLLY, M.M. Relação do teste de Alizarol a $72 \%$ (v/v) em leite "in natura" de vaca com acidez e contagem de células somáticas: análise microbiológica. Rev. Hig. Alim., v.17, p.95-100, 2003.

MARQUES, L.T. Ocorrência do leite instável não ácido (LINA) e seu efeito sobre a composição química e aspectos físicos. 2004. 68f. Dissertação (Mestrado) - Universidade Federal de Pelotas, Pelotas, RS.

MÜHLBACH, P.R.F.; OSPINA, H.; PRATES, E.R. et al. Aspectos nutricionais que interferem na qualidade do leite. In: ENCONTRO ANUAL DA UFRGS SOBRE NUTRIÇÃO DE RUMINANTES. Porto Alegre: UFRGS, 2000. p.73-102

NEGRI, L.; CHAVEZ, M.; TAVERNA, M. et al. Fatores que afectan la estabilidad térmica y la prueba de alcohol en leche cruda de calidad higiénica adecuada: Informe técnico final Del proyecto. Rafaela: INTA EEA/INTI CITIL, 2001.27p

PONCE CEBALLO, P. Síndrome do leite anormal e qualidade do leite. In: Curso on line sobre qualidade do leite do Instituto Fernando Costa. Disponível em: 
$<$ http//www.milkpoint.com.br $>$ Acessado em: 17 nov. 2000.

PONCE CEBALLO, P.; HERNÁNDEZ, R. Propriedades físico-químicas do leite e sua associação com transtornos metabólicos e alterações na glândula mamária. In: GONZÁLEZ, F.H.D.; DÜRR, J.W.; FONTANELI, R.S. (Ed.). Uso do leite para monitorar a nutrição e metabolismo de vacas leiteiras. Porto Alegre: UFRGS, 2001. p.58-68
SOBHANI, S.; VALIZADEH, R.; NASERIAN, A. Alcohol stability of milk and its relation to milk and blood composition in Holstein dairy cows. J. Dairy. Sci., v.85, Suppl. 1, p.58, 1998.

ZANELA, M.B. Caracterização do leite produzido no Rio Grande do Sul, ocorrência e indução experimental do Leite Instável Não Ácido (LINA). 2004. 175f. Tese (Doutorado) Universidade Federal de Pelotas, Pelotas, RS. 